\title{
Teachers Activities at ICME-13
}

\author{
Nils Buchholtz, Marianne Nolte and Gabriele Kaiser
}

The 13th International Congress on Mathematical Education in Hamburg was not only a scientific experience for researchers in mathematics education from all over the world. As Convenor and Local Chair of ICME-13, we are particularly pleased that also more than 250 teachers from all over Germany and five other countries have benefited from this congress. Despite the school holidays taking place in many federal states of Germany in July, mathematics teachers could take part in a special conference for teachers taking place parallel to ICME-13 on the 27th-29th of July 2017. On three days, the teachers were able to participate in a comprehensive lecture and workshop program, which included not only professional development courses in the area from primary to secondary mathematics education, but also thematically relevant excursions. A special highlight was already offered to the teachers before the official opening ceremony of the conference for teachers. They were allowed to participate at the ICME-13 Plenary Session by Günter Ziegler: "What is mathematics? - and why we should ask, where one should learn that, and who can teach it?" and thus take a look at the regular conference program.

The opening ceremony for the teachers at the Auditorium Maximum gave the expected program an appropriate setting. The opening speeches of Gabriele Kaiser (Convenor of ICME-13), Rudolf vom Hofe (President of the German Society of Didactics of Mathematics), State Councilor Michael Voges (Hamburg School Authority) and Marianne Nolte (Local Chair of ICME-13) were marked by the appreciation of the work of the colleagues from the school practice, but they also

Nils Buchholtz (Member of the Local Organizing Committee), Marianne Nolte (Local Chair of ICME-13), Gabriele Kaiser (Convenor of ICME-13).

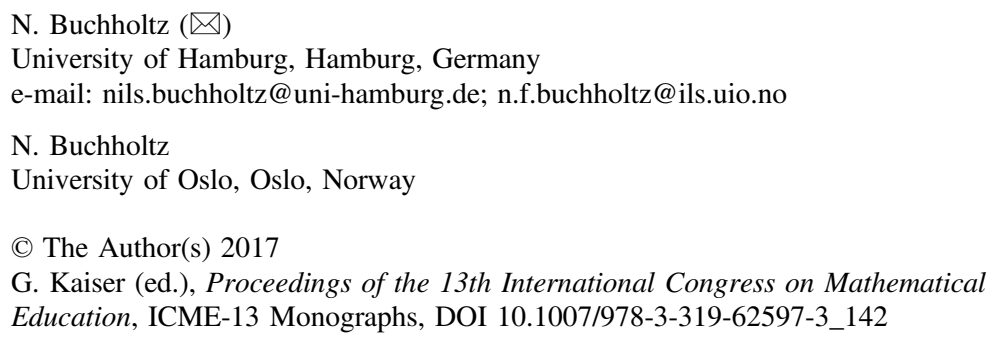


discussed the importance of continuing professional development of teachers facing an increasing heterogeneity of students in schools. In this respect, the opportunities of professional development of ICME-13 were certainly unique. In his lecture on "Mathematical experiments - little effort, great impact" with many illustrations and mathematical experiments Albrecht Beutelspacher subsequently got the teachers in the right mood for the following sessions. Luckily, many members from the German Society of Didactics of Mathematics and the German Teacher Association for the Advancement of Mathematics and Natural Science Teaching (MNU) agreed to participate in the lecture and workshop program. With the offered excursions, the teachers also had some opportunities to get to know about teaching-relevant out-of-school learning opportunities, which provide mathematical and scientific learning content for students For example, the teachers were able to visit the logistics of the Hamburg harbor, learn experiments in a student laser laboratory, gain an insight into Hamburg's aluminum smelting and processing, explore the connections between mathematics and art in the Hamburg Art Gallery or take a mathematical city walk through the Hamburg city center. In the Auditorium Maximum, the teachers were able to visit the mathematical exhibition in guided tours and put their "hands on" many mathematical exhibits.

Open Access Except where otherwise noted, this chapter is licensed under a Creative Commons Attribution 4.0 International License. To view a copy of this license, visit http://creativecommons. org/licenses/by/4.0/.

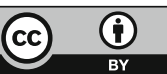

